\title{
A PARTICIPACIÓN No MERCADO DE VALORES: POR QUE INVISTEN OS INDIVIDUOS?1
}

TANIA PUMARES IGLESIAS*

tania.pumares@rai.usc.es

SARA FERNÁNDEZ LÓPEZ*

sara.fernandez.lopez@usc.es

MiLAGROSVIVEL BÚA*

mila.vivel@usc.es

LUCÍA REY ARES*

lucia.rey@usc.es

Resumo: A participación no mercado bolsista é un tema de estudo con varias décadas de historia, aínda hoxe en discusión, como resposta á persistencia de baixas taxas de participción. Neste traballo analízanse os determinantes da participación no devandito mercado mediante modelos probit, onde a variable dependente recolle a tenza directa de accións e/ ou a participación indirecta a través de fondos de investimento. Os resultados amosan que a idade, educación, preferencias de risco e uso de internet resultan ser variables chaves á hora de explicar a participación dos fogares no mercado de valores na España.

Palabras chave: determinantes, individuo, investimento, mercado bolsista.

\section{STOCK MARKET PARTICIPATION: WHY DO PEOPLE INVEST?}

Abstract: Stock market participation is an issue which has been studied since the 90's, but academics are still worried about it nowadays because of the persistence of low participation rates. This paper studies the factors which drive stock market participation through probit estimations. The dependent variable groups direct stock market participation (having stocks) and indirect stock market participation (having mutual funds participations). The results show that age, education, risk attitudes and use of internet are key variables to explain household stock market participation in Spain. Keywords: determinants, person, investment, stock market.

\section{INTRODUCIÓN}

Na actualidade os fogares están máis implicados nas tomas de decisión económicas ca no pasado, o cal pode ter como causas a liberalización dos mercados e a expansión do crédito (Guiso e Sodini, 2012). A participación no mercado de valores constitúe unha decisión de carácter económico para os fogares, como o é a contratación de seguros, a compra de bens ou servizos, e o aforro. Pero malia que os fogares teñen hoxe un papel máis activo, as taxas de participación no mercado de valores seguen en niveis relativamente baixos no ámbito europeo, por exemplo, arredor do 30\% para Reino Unido ou ao 22\% para Alemaña, e en niveis moi baixos para o caso de España, situándose arredor dun 5\% (Guiso e Sodini, 2012). No caso latinoamericano, a situación non difire moito. Así, no ano 2012, un 3,4\% dos fogares en Chile posuía algún tipo de activo financeiro de renda variable -accións, fondos mutuos ou participacións en sociedades, entre outros activos- (Banco Central de Chile, 2013). Por outra banda, só un 0,7\% da poboación en Colombia inviste en accións, fondos ou bonos (Serrano e Hoesli, 2009).

\footnotetext{
* Enderezo para correspondencia: Facultade de Ciencias Económicas e Empresariáis. Universidade de Santiago de Compostela; Avda. Burgo das Nacións, s/n; C.P. 15.782 - Santiago de Compostela (España).

1 Esta investigación utiliza datos da Survey of Health, Ageing and Retirement in Europe (SHARE). Os autores agradecemos a súa cesión para fins de investigación.
} 
Desde finais dos anos 90 e, sobre todo, a partir de inicios do século XXI, varios traballos centraron a súa atención en tratar de atopar os factores que determinan a decisión de participar no mercado bolsista. O seu fin último é explicar por que as taxas de participación sitúanse nunhas cifras tan baixas, tendo en conta o gran desenvolvemento, tanto financeiro como tecnolóxico, experimentado nas últimas décadas. Ademais, a crise económica e financeira actual protagonizou unha gran volatilidade nos mercados de valores, o que sen dúbida ten e terá tamén consecuencias sobre as decisións económicas dos fogares, e polo tanto, sobre a participación nos devanditos mercados.

Malia a ampla literatura dispoñible sobre o tema, non existen traballos que investiguen en detalle os determinantes da participación no mercado de valores para o caso español en concreto, pois a maioría fano a un nivel máis agregado como é o contexto europeo. De feito, polo que sabemos, só existe unha referencia previa para España que é o estudo de Ampudia Frade (2013), aínda que este subscríbese ao ano 2005 e non analiza un conxunto tan amplo de determinantes de investimento como o que se aplica nesta investigación. Igualmente, as investigacións centradas na realidade latinoamericana, próxima económica e culturalmente á española, tamén son escasas. Por este motivo, o obxectivo deste traballo é realizar unha análise e descrición específica dos factores que están determinando a propensión dos fogares a participar no mercado de valores en España, a partir do estudo dun conxunto de variables propostas na literatura académica. Deste xeito, esta investigación pode constituír un bo punto de partida para investigacións posteriores, por exemplo, en Latinoamérica, dadas as baixas taxas de participación bolsista, próximas ás atopadas para España, e da proximidade cultural.

Tras esta introdución, o resto do documento está organizado da seguinte forma. No segundo epígrafe preséntase unha sinopse das principais achegas realizadas pola literatura financeira previa. $\mathrm{O}$ terceiro epígrafe destínase ao comentario dos resultados empíricos obtidos a través da análise estatística-descritiva e a econométrica. Finalmente, o último epígrafe recolle as conclusións e limitacións do estudo, así como o comentario das posibles implicacións cara ao deseño da futura política económica.

\section{REVISIÓN DA LITERATURA E FORMULACIÓN DE HIPÓTESES}

Dende a teoría financeira máis tradicional faise fincapé en factores tales como a aversión ao risco, as oportunidades de investimento e os custos fixos asociados para tratar de explicar as decisións de investimento dos individuos e fogares. No entanto, achegas recentes incorporaron á análise un maior e máis variado número de variables que poden influír na participación no mercado de valores. Desta forma, podemos atopar factores como o activismo e as preferencias políticas, a confianza, a cultura financeira, o asesoramento financeiro, o uso de tecnoloxías ou a interacción social, entre outras.

A Táboa 1 amosa os resultados dalgúns dos estudos máis recentes e de maior relevancia empírica no tema de estudo. Estes traballos teñen como obxectivo principal coñecer a influencia dun determinado factor na participación dos fogares nos mercados de valores. A partir da revisión destes traballos, sinalamos a continuación os factores que poderían actuar como determinantes da decisión dos individuos de investir no mercado de valores, ao mesmo tempo que se establecen as hipóteses que se contrastarán na análise empírica (Táboa 2). 
Táboa 1: Resumo dos principais traballos empíricos relacionados coa participación no mercado de valores

\begin{tabular}{|c|c|c|c|c|}
\hline $\begin{array}{c}\text { Variable } \\
\text { principal de } \\
\text { estudo } \\
\end{array}$ & Autores & $\begin{array}{l}\text { Variable dependente } \\
\text { (modelo) }\end{array}$ & Mostraxe da análise & Resultados \\
\hline \multirow[t]{2}{*}{ Confianza } & \multirow[t]{2}{*}{$\begin{array}{l}\text { Guiso et al. } \\
(2008)\end{array}$} & $\begin{array}{l}\text { Participación no } \\
\text { mercado de valores } \\
\text { (probit) }\end{array}$ & $\begin{array}{c}1.156 \text { fogares dos } \\
\text { Países Baixos (Banco } \\
\text { Nacional de Holanda). } \\
\text { Enquisa aos fogares } \\
(2003) \\
\end{array}$ & $\begin{array}{l}\text { Confianza xeral }(+) \text {; Riqueza } \\
\text { financeira }(+) ; \\
\text { Educación universitaria }(+) \text {; } \\
\text { Idade ao cadrado }(+) ; \\
\text { Idade }(-)\end{array}$ \\
\hline & & $\begin{array}{l}\text { Propiedade de } \\
\text { activos con risco } \\
\text { (probit) }\end{array}$ & $\begin{array}{l}1.834 \text { persoas en Italia. } \\
\text { Enquisa a clientes de } \\
\text { bancos italianos } \\
(2003)\end{array}$ & $\begin{array}{l}\text { Confianza específica alta }(+) \text {; } \\
\text { Riqueza financeira }(+) \text {; Xénero } \\
\text { masculino }(+) ; \\
\text { Educación }(+) ; \text { Idade }(+) ; \\
\text { Idade ao cadrado }(-)\end{array}$ \\
\hline $\begin{array}{l}\text { Confianza e } \\
\text { educación }\end{array}$ & $\begin{array}{l}\text { Georgarakos } \\
\text { e Inderst } \\
(2011)\end{array}$ & $\begin{array}{l}\text { Propiedade de } \\
\text { activos con risco } \\
\text { (probit) }\end{array}$ & $\begin{array}{l}7.527 \text { persoas de } \\
\text { Europa. } \\
\text { Enquisa do } \\
\text { Eurobarómetro } \\
\text { (2003) }\end{array}$ & $\begin{array}{l}\text { Confianza específica no } \\
\text { consello financeiro (+); } \\
\text { Ingresos (+); Protección } \\
\text { dereitos consumidores }(+) ; \\
\text { Idade }(+) \text {; Xénero masculino } \\
(+) \text {; Emprendedores }(+) ; \\
\text { Educación universitaria (+); } \\
\text { Parellas (-); Divorciados/ as (-) }\end{array}$ \\
\hline $\begin{array}{c}\text { Cultura } \\
\text { financeira }\end{array}$ & $\begin{array}{c}\text { Van Rooij et } \\
\text { al. } \\
(2011)\end{array}$ & $\begin{array}{l}\text { Participación no } \\
\text { mercado de valores } \\
\text { (OLS, GMM) }\end{array}$ & $\begin{array}{c}2.000 \text { fogares dos } \\
\text { Países Baixos (Banco } \\
\text { Nacional de Holanda). } \\
\text { Enquisa aos fogares } \\
(2005)\end{array}$ & $\begin{array}{l}\text { Cultura financeira (+); Idade } \\
(+) \text {; Ingresos (+); } \\
\text { Riqueza (+); Reducido } \\
\text { coñecemento sobre accións (- } \\
\text { ); Individuos financeiramente } \\
\text { pouco sofisticados (-); Xénero } \\
\text { feminino (-); Estudos (-) }\end{array}$ \\
\hline $\begin{array}{l}\text { Consello } \\
\text { financeiro }\end{array}$ & $\begin{array}{l}\text { Direr } \\
\text { e Viser } \\
\text { (2013) }\end{array}$ & $\begin{array}{c}\text { Parte do capital } \\
\text { investido en renda } \\
\text { variable (método de } \\
\text { estimación proposto } \\
\text { por Papke e } \\
\text { Wooldridge }(1996)) \\
\end{array}$ & $\begin{array}{l}24.374 \text { persoas en } \\
\text { Francia. Empresa } \\
\text { financeira francesa } \\
\text { (2004-2005) }\end{array}$ & $\begin{array}{l}\text { Formación do asesor } \\
\text { Financeiro (+); Xénero } \\
\text { feminino do asesor financeiro } \\
(-) \text {; Idade }(-)\end{array}$ \\
\hline \multirow[t]{2}{*}{ Idade } & \multirow[t]{2}{*}{$\begin{array}{l}\text { Fujiki } \\
\text { et al. } \\
(2012)\end{array}$} & $\begin{array}{l}\text { Participación no } \\
\text { mercado de valores } \\
\text { (probit) }\end{array}$ & \multirow{2}{*}{$\begin{array}{c}8.000 \text { fogares no } \\
\text { Xapón (Consello } \\
\text { Central de Servizos de } \\
\text { Información } \\
\text { Financeira). } \\
\text { Enquisa das finanzas } \\
\text { dos fogares } \\
(2007-2010)\end{array}$} & $\begin{array}{l}\text { Idade(+); Ingresos (+); } \\
\text { Tamaño familiar (-); } \\
\text { Ocupación: autónomo e } \\
\text { agricultor (-); Aforro para } \\
\text { gastos fututos (+) }\end{array}$ \\
\hline & & $\begin{array}{l}\text { Porcentaxe de } \\
\text { accións nos activos } \\
\text { financeiros dun } \\
\text { fogar (probit) }\end{array}$ & & $\begin{array}{l}\text { Ingresos (+); Preferencia por } \\
\text { transaccións financeiras } \\
\text { online }(+) \text {; Aforro para gastos } \\
\text { fututos }(+)\end{array}$ \\
\hline \multirow[t]{2}{*}{ Xénero } & $\begin{array}{l}\text { Almenberg } \\
\text { e Dreber } \\
(2011)\end{array}$ & $\begin{array}{l}\text { Participación no } \\
\text { mercado de valores } \\
\text { (probit) }\end{array}$ & $\begin{array}{c}1.300 \text { persoas entre } 18 \\
\text { e } 79 \text { anos de Suecia } \\
\text { (Autoridade sueca de } \\
\text { supervisión financeira } \\
\text { ) } \\
(2010) \\
\end{array}$ & $\begin{array}{l}\text { Risco tomado }(+) \text {; Ingresos } \\
(+) \text {; Cultura financeira }(+) \text {; } \\
\text { Género femenino }(-)\end{array}$ \\
\hline & $\begin{array}{l}\text { Christiansen } \\
\text { et al. } \\
(2010)\end{array}$ & $\begin{array}{l}\text { Participación no } \\
\text { mercado de valores } \\
\text { (probit) }\end{array}$ & $\begin{array}{l}1.939 .383 \text { persoas } \\
\text { entre } 20 \text { e } 60 \text { anos de } \\
\text { Dinamarca (Instituto } \\
\text { dinamarqués de } \\
\text { investigación } \\
\text { gobernamental). }\end{array}$ & $\begin{array}{l}\text { xénero masculino (+); Estado } \\
\text { civil casado/ a (+); } \\
\text { Idade (+); Educación }(+) ; \\
\text { Ingresos (+); Riqueza (+); } \\
\text { Cultura financeira: } \\
\text { economista (+); Número de } \\
\text { fillos/ as (-) }\end{array}$ \\
\hline
\end{tabular}




\begin{tabular}{|c|c|c|c|c|}
\hline & & & (1997-2003) & \\
\hline \multirow[t]{2}{*}{$\begin{array}{l}\text { Internet e as } \\
\text { tecnoloxías } \\
\text { da } \\
\text { información }\end{array}$} & \multirow[t]{2}{*}{$\begin{array}{c}\text { Ampudia } \\
\text { Fraile (2013) }\end{array}$} & $\begin{array}{l}\text { Tenza directa de } \\
\text { accións (Modelo de } \\
\text { selección de } \\
\text { Heckman) }\end{array}$ & \multirow[t]{2}{*}{$\begin{array}{c}5.962 \text { fogares de } \\
\text { España. } \\
\text { Enquisa Financeira das } \\
\text { Familias (2005) }\end{array}$} & $\begin{array}{l}\text { Estado civil: casado }(+) ; \\
\text { Estudos: universitarios }(+) ; \\
\text { Idade: }>51 \text { anos }(+) ; \text { Ingresos } \\
(+) \text {; Riqueza neta }(+) ; \\
\text { propensión ao risco }(+) ; \\
\text { traballo en finanzas }(+) ; \\
\text { utilización banca electrónica } \\
(+)\end{array}$ \\
\hline & & $\begin{array}{l}\text { Tenza indirecta de } \\
\text { accións (Modelo de } \\
\text { selección de } \\
\text { Heckman) }\end{array}$ & & $\begin{array}{l}\text { Estado civil: casado }(+) ; \\
\text { Estudos: universitarios }(+) ; \\
\text { Idade: }>41 \text { años }(+) \text {; Ingresos } \\
(+) \text {;Riqueza neta }(+) ; \\
\text { propensión ao risco }(+) ; \\
\text { traballo en finanzas }(+) ; \\
\text { utilización banca electrónica } \\
(+)\end{array}$ \\
\hline $\begin{array}{l}\text { Preferencias } \\
\text { de risco e } \\
\text { xénero }\end{array}$ & $\begin{array}{l}\text { Halko et al. } \\
\text { (2011) }\end{array}$ & $\begin{array}{l}\text { Participación no } \\
\text { mercado de valores } \\
\text { (probit) }\end{array}$ & $\begin{array}{c}66.795 \text { clientes } \\
\text { minoristas bancarios } \\
\text { de Finlandia }(2011)\end{array}$ & $\begin{array}{l}\text { Idade }(+) \text {; Coñecemento de } \\
\text { inversións }(+) \text {; Educación }(+) \text {; } \\
\text { Risco financeiro tomado }(+) \text {; } \\
\text { Xénero feminino }(-)\end{array}$ \\
\hline $\begin{array}{l}\text { Relixiosidade, } \\
\text { interacción } \\
\text { social e } \\
\text { preferencias } \\
\text { políticas }\end{array}$ & $\begin{array}{l}\text { Laakso } \\
(2010)\end{array}$ & $\begin{array}{c}\text { Propiedade de } \\
\text { accións (probit) }\end{array}$ & $\begin{array}{l}34.415 \text { participantes } \\
\text { de diversos países } \\
\text { europeos. } \\
\text { Enquisa SHARE, } \\
\text { segunda "vaga". (2006- } \\
\text { 2007) }\end{array}$ & $\begin{array}{l}\text { Xénero masculino (+); Idade } \\
\text { ao cadrado }(+) \text {; Educación }(+) \text {; } \\
\text { Riqueza }(+) ; \\
\text { Aversión ao risco }(-) \text {; } \\
\text { Interacción social }(+) \text {; } \\
\text { Confianza }(+) \text {; Preferencias } \\
\text { políticas “de dereitas" (+); } \\
\text { Habilidades cognitivas (+); } \\
\text { Estado de saúde pobre }(-) ; \\
\text { Satisfacción vital }(+) \text {; Relixión } \\
(+)\end{array}$ \\
\hline
\end{tabular}

Tabla 2: Hipóteses

\begin{tabular}{|c|c|}
\hline Factor(signo esperado) & Hipótese: Espérase unha relación...e a súa decisión de participar no mercado de valores \\
\hline Idade $(+)$ & ...positiva entre a ideade da persoa \\
\hline Xénero $(+)$ & ...positiva entre ser Home e a decisión de participar no mercado de valores. \\
\hline Estado civil $(+)$ & ...positiva entre os fogares formados por parellas . \\
\hline Número de fillos(-) & ...negativa entre os fogares con maior número de fillos ao seu cargo \\
\hline Ingresos $(+)$ & ...positiva entre o nivel de ingresos da persoa . \\
\hline Ocupación $(+)$ & ...positiva entre estar empreado/a \\
\hline Propiedade vivenda (-) & ...negativa entre ser propietario/a dunha vivenda \\
\hline Educación (+) & ...positiva entre o nivel educativo da persoa . \\
\hline Cultura financeira $(+)$ & ...positiva entre o nivel de cultura financeira da persoa \\
\hline Preferencias de risco (-) & ....negativa entre ser adverso/a ao risco \\
\hline Confianza $(+)$ & ... positiva entre o nivel de confianza da persoa \\
\hline Uso de Internet(+) & ...positiva entre o uso de Internet \\
\hline Satisfacción vital $(+)$ & ...positiva entre o nivel de satisfacción vital da persoa \\
\hline Preferencias políticas (+) & ...positiva entre una orientación política de "dereitas" \\
\hline Relixiosidad $(+)$ & ...positiva entre practicar unha relixión \\
\hline Interacción social (+) & ...positiva entre a participación en actividades sociales \\
\hline
\end{tabular}

FONTE: elaboración propia. Definicións das variables no Anexo 1. 


\section{METODOLOXÍA}

\subsection{1. MOSTRA DE ESTUDO}

Esta investigación utiliza como fonte de datos a Survey of Health, Ageing and Retirement in Europe, coordinada polo Mannheim Research Institute for the Economics of Ageing (Táboa 3). SHARE é un panel de datos multidisciplinar realizado en países europeos para recoller información sobre o estatus socioeconómico, a saúde e as redes sociais dos participantes na enquisa, así como dos seus cónxuxes ou parellas. Ademais, proporciona información relacionada con variables psicolóxicas e de apoio social. É unha enquisa dinámica que procura realizar o seguimento dos mesmos participantes na enquisa e doutros novos.

Este traballo utiliza información contida na cuarta edición, por razóns de proximidade temporal e de deseño do cuestionario. A mostra final confórmase polos fogares españois que participaron na enquisa ao longo do ano 2011.

\section{Táboa 3. Información técnica do estudo}

$\begin{array}{ll}\text { Universo } & \begin{array}{l}\text { Persoas de } 50 \text { anos ou máis, e o seus cónxuxes ou parellas con independencia da } \\ \text { súa idade. }\end{array}\end{array}$

Método da entrevista Entrevista Persoal Asistida por Ordenador, complementada cun breve cuestionario en papel autocumprimentado.

\begin{tabular}{ll}
\hline Selección da mostra & $\begin{array}{l}\text { Mostraxe en dúas etapas: 1) Selección de distritos censais entre unha lista } \\
\text { estratificada por tamaño de municipio; 2) Selección de fogares con persoas } \\
\text { elixbles de cada un dos distritos censais seleccionados. }\end{array}$ \\
\hline Tamaño da mostra & 3.570 entrevistas en España \\
\hline Recollida de información & Ano 2011 \\
\hline Publicación de datos & Novembro 2012 \\
\hline
\end{tabular}

Fonte: elaboración propia a partir de SHARE.No Anexo 1 inclúese a Táboa 4.

\section{ANÁLISE EMPÍRICA}

\subsection{ANÁLISE ESTATÍSTICA - DESCRITIVA}

As estatísticas descritivas das variables incluídas nesta investigación detállanse na Táboa 5. Antes de nada, debe sinalarse que a mostra inicial foi filtrada por razóns de estudo, eliminando da mesma aos participantes na enquisa cunha idade superior a 80 anos.

En relación coa variable dependente, obsérvase que as taxas de participación no mercado de valores en España son moi baixas. Menos do 6\% das persoas que participaron na enquisa afirmaron que posuían accións e/ ou participacións en fondos de investimento. Estas cifras contrastan coas apuntadas para 2005 por Ampudia Frade (2013), que indicaban que un 13,05\% dos fogares españois participaba directamente nos mercados mediante accións e un 16,68\% facíao indirectamente mediante fondos de investimento. As razóns de tales divergencias poden obedecer fundamentalmente a dúas cuestións. Por unha banda, a mostra utilizada por Ampudia Frade (2013) abarca individuos que van dende os 16 anos ata máis de 70, mentres SHARE céntrase naqueles que superan os 50 anos. Como se indicou, a maior idade, menor propensión ao risco e menor investimento no mercado de valores. Doutra banda, en 2005 a situación "eufórica" dos mercados de valores españois, e da economía en xeral, era radicalmente oposta á existente en 2011, que escorrentou aos inversores do mercado de valores español. 
Táboa 5: Estatísticas descritivas

\begin{tabular}{|c|c|c|c|c|c|}
\hline VARIABLE & OвS. & MEDIA & $\begin{array}{l}\text { DESVIACIÓN } \\
\text { TíPICA }\end{array}$ & MÍNIMO & MÁxIMO \\
\hline $\begin{array}{l}\text { Participación no mercado de valores } \\
\text { (accións / fondos de inversión) }\end{array}$ & 1.841 & 5,81 & & 0 & 1 \\
\hline Idade & 3.048 & 64,72 & 8,97 & 28 & 80 \\
\hline Xénero & 3.048 & 0,46 & 0,5 & 0 & 1 \\
\hline Estado civil & 1.662 & 0,81 & 0,39 & 0 & 1 \\
\hline № de fillos & 1.875 & 2,35 & 1,58 & 0 & 14 \\
\hline Ingresos & 1.415 & $4.793,08$ & $13.030,75$ & 20 & 360.000 \\
\hline Ocupación & 3.027 & 0,23 & 0,42 & 0 & 1 \\
\hline Propiedade vivenda & 1.858 & 0,92 & 0,27 & 0 & 1 \\
\hline Educación & 1.612 & 8,41 & 5,06 & 0 & 25 \\
\hline Cultura financeira & 258 & 0,19 & 0,39 & 0 & 1 \\
\hline Aversión ao risco & 1.564 & 0,87 & 0,33 & 0 & 1 \\
\hline Confianza & 1.573 & 0,44 & 0,50 & 0 & 1 \\
\hline Internet & 1.593 & 0,27 & 0,44 & 0 & 1 \\
\hline Satisfacción vital & 2.920 & 0,87 & 0,34 & 0 & 1 \\
\hline Preferencias políticas & 1.336 & 0,22 & 0,41 & 0 & 1 \\
\hline Relixiosidade & 1.579 & 0,47 & 0,50 & 0 & 1 \\
\hline Interacción social & 2.996 & 0,20 & 0,40 & 0 & 1 \\
\hline
\end{tabular}

Nota: a táboa 5 amosa as estatísticas descritivas das variables analizadas. As variables continuas amósanse na súa forma orixinal, isto é, sen transformación logarítmica. "Obs." indica o número de observacións. O valor da media para as variables dicotómicas informa do valor en tanto por un de persoas que cumpren a condición segundo a cal estas variables toman o valor igual á unidade.

En relación coas variables independentes, comprobamos que a mostra de estudo está formada por individuos cuxa media de idade atópase nos 64 anos, maioritariamente son mulleres (54\%) e manifestan ter un compromiso de parella (81\%) cun número medio de fillos próximo a dous. Así mesmo, o saldo medio de ingresos mensuais supera os 4.700 euros, máis do $90 \%$ dos participantes na enquisa manifesta ter unha vivenda en propiedade, e só unha media do $23 \%$ traballa por conta propia ou allea. Isto último é debido a que o colectivo máis numeroso da mostra corresponde aos xubilados (37\%), que se situaría dentro do grupo de persoas que non traballan. De feito, só o $27 \%$ dos participantes na enquisa afirma usar Internet, feito que se pode relacionar directamente coa idade, pois tipicamente o uso é menor entre a xente de idade máis avanzada.

Referente ao nivel educativo, o número medio de anos de estudo a tempo completo sitúase en 8, o cal corresponderiase coa educación secundaria. Ao prestarlle atención aos 
coñecementos financeiros do participante, o primeiro a destacar é o baixo número de persoas que se amosaron dispostas a contestar á pregunta relativa a esta cuestión, e o segundo, o baixo nivel de alfabetización financeira daquelas persoas que responderon. De feito, só un 19\% das persoas que responden á pregunta sobre o cálculo do nominal e os intereses dunha conta de aforro faino de forma correcta. No entanto, esta baixa taxa de éxito na resposta é consistente cos resultados que atopa Jappelli (2010) cando compara o nivel de cultura económica (utilizada como proxy da cultura financeira) utilizando datos do IMD World Competitiveness Yearbook dende 1995 ata 2004, e situando a España moi por baixo de Estados Unidos e do resto dos países da OCDE coa excepción de Italia.

No caso da variable que mide as preferencias de risco, a conclusión principal é que a actitude que predomina entre os participantes é a dunha clara aversión ao risco. De feito, un $87 \%$ da mostra di non estar disposto a asumir ningún risco financeiro. Pola súa banda, un 56\% dos participantes non teñen confianza nas demais persoas e só un $20 \%$ participou nalgunha actividade social. Agora ben, un 87\% manifesta estar satisfeito coa súa vida. A orientación política dos participantes sitúase máis próxima á esquerda, xa que só un $22 \%$ declara unha ideoloxía política de dereitas. Por outra banda, un $47 \%$ practica unha relixión.

A Táboa 6 recolle as diferenzas que poden existir entre inversores e non inversores no mercado de valores en relación ás variables independentes, así como o seu nivel de significatividade. Constátanse diferenzas significativas nas variables: ocupación, propiedade dunha vivenda, educación, risco, Internet e orientación política.

Táboa 6: Diferenza de medias das variables independentes

\begin{tabular}{|l|c|c|c|c|}
\hline VARIABLE & OBS. & $\begin{array}{c}\text { PARTICIPAN NO } \\
\text { MERCADO DE VALORES } \\
\text { (MEDIA) }\end{array}$ & $\begin{array}{c}\text { NON PARTICIPAN NO MERCADO } \\
\text { DE VALORES } \\
\text { (MEDIA) }\end{array}$ & P-VALUE \\
\hline Idade & 1.841 & 64,6 & 64,91 & 0,71 \\
\hline Xénero & 1.841 & 0,48 & 0,42 & 0,27 \\
\hline Estado civil & 1.005 & 0,70 & 0,71 & 0,92 \\
\hline № de fillos & 1.727 & 2,11 & 2,36 & 0,12 \\
\hline Ingresos & 1.406 & $5.554,43$ & $4.727,14$ & 0,57 \\
\hline Ocupación & 1.836 & 0,31 & 0,22 & 0,03 \\
\hline Propiedade vivenda & 1.834 & 0,97 & 0,91 & 0,03 \\
\hline Educación & 963 & 11,85 & 8,21 & 0,00 \\
\hline Cultura financeira & 139 & 0,1 & 0,18 & 0,39 \\
\hline Aversión ao risco & 949 & 0,47 & 0,89 & 0,00 \\
\hline Confianza & 954 & 0,53 & 0,46 & 0,18 \\
\hline Internet & 963 & 0,62 & 0,25 & 0,00 \\
\hline Satisfacción vital & 1.751 & 0,92 & 0,87 & 0,16 \\
\hline Preferencias políticas & 799 & 0,43 & 0,21 & 0,01 \\
\hline Relixiosidade & 957 & 0,48 & 0,49 & 0,92 \\
\hline Interacción social & 1.811 & 0,27 & 0,21 & 0,09 \\
\hline
\end{tabular}

Nota: a táboa 6 amosa a análise da diferenza de medias en función da participación do individuo analizado no mercado de valores. Un p-value inferior a 0,05 implica que existen diferenzas significativas entre as persoas que participan no mercado de valores e as que non o fan.

En particular, as persoas que participan no mercado bolsista presentan porcentaxes de ocupación laboral, niveis educativos, porcentaxes de uso de Internet e niveis de propiedade de vivenda máis elevados. Así mesmo, presentan menor aversión ao risco e unhas preferencias políticas máis próximas "á dereita". 


\subsection{ANÁLISE ECONOMÉTRICA MULTIVARIANTE}

Estimáronse oito modelos diferentes (Táboa 7 no Anexo), incluíndo no primeiro modelo (Modelo 1) variables tales como a idade, a idade ao cadrado, a aversión ao risco, a educación e o feito de estar empregado. Ditas variables pertencen aos catro grandes grupos de factores que, tras analizar a literatura, consideráronse básicos, a saber, demográficos, relativos ás preferencias de risco, educacionais e económicos. Os seguintes modelos (modelos 2-8) van engadindo variables co fin de contrastar todas as hipóteses suscitadas.

Os resultados obtidos amosan que, contrariamente ao esperado, a idade exerce un efecto negativo sobre a participación no mercado de valores para o caso español. Este efecto podería atribuírse, polo menos en parte, a que as persoas de maior idade invisten en activos con risco, tales como accións e fondos de investimento, en menor medida que os mozos (Direr e Viser, 2013; Dohmen et a 0., 2011).

Ademais, atopáronse relacións non lineais, xa que a idade ao cadrado tamén resultou significativa e con signo positivo. Estes resultados indican que existe unha relación en forma de U entre a idade dos individuos da mostra ${ }^{2}$ e a participación no mercado de valores. Este resultado podería atribuírse a que en idades próximas aos 50-55 anos, os individuos aínda destinan unha parte importante dos seus ingresos ao pago de hipotecas, o que limitaría a súa capacidade de aforro e, por tanto, os fondos dispoñibles para colocar no mercado de valores. Con todo, acadada unha determinada idade na que os préstamos estivesen amortizados, os individuos terían máis capacidade de aforro e, consecuentemente, saldos dispoñibles para colocar no mercado de valores.

O feito de ser adverso ao risco inflúe negativamente na participación no mercado de valores. Algúns traballos miden a variable risco como aquela que toman os individuos que participan nos devanditos mercados, de modo que obteñen resultados positivos entre 0 risco asumido e a participación (Almenberg e Dreber, 2011; Dohmen et a o., 2011; Halko, Kaustia e Alanko, 2011). Por tanto, destes traballos pódese concluír que, se o nivel de risco tomado é moi baixo, a participación será menor, o cal coincide cos nosos resultados, confirmándose así a hipótese de que aqueles individuos adversos ao risco participan no mercado de valores en menor medida que os individuos propensos ao mesmo. Isto débese a que os individuos adversos non cren que a expectativa dunha maior ganancia xustifique a asunción dun risco maior.

Cómpre destacar que esta variable relativa á actitude do individuo ante o risco puido ter unha especial relevancia no momento no que se realizou a enquisa SHARE. Como xa se comentou, os datos utilizados refírense ao ano 2011, época na que os mercados de valores, especialmente os españois, estaban -e aínda están- vivindo un momento de gran incerteza trala forte caída dos índices bolsistas de todo o mundo e a crise da débeda pública española. Nunha contorna con estas características, os inversores máis adversos amosarianse aínda máis reticentes que en condicións normais á participación no mercado de valores.

A educación tamén resulta unha variable significativa na maioría dos modelos estimados, e ten un efecto positivo sobre a participación no mercado de valores. Autores como Bogan (2008), Christiansen, Joensen e Rangvid (2010a), Cole, Paulson e Shastry (2012) ou Guiso, Sapienza e Zingales (2008) tamén obtiveron este resultado. Por tanto, a hipótese suscitada de que, ante un maior nivel de educación, a participación no mercado tamén é maior, confírmase. Iso fundaméntase en que a educación posibilita un aumento das habilidades que posúen as persoas para solicitar información, especialmente no caso daquelas de

2 Nótese que o 97\% dos individuos da mostra teñen máis de 50 anos. 
natureza informática e cognitiva, as cales son de gran utilidade á hora de investir nos mercados bolsistas.

A variable relativa ao uso de internet resultou significativa e con signo positivo, do mesmo xeito que no traballo de Bogan (2008). Desta forma, confírmase que a súa utilización aumenta a probabilidade de que os individuos participen no mercado de valores, ao constituír unha forma de coñecer as tecnoloxías que se poden usar para participar no devandito mercado. Ademais, como suxire Ampudia Frade (2013), o comercio en liña permite reducir non só o custo monetario derivado do investimento, senón tamén o custo en tempo.

En contraposición á evidencia atopada por Guiso, Sapienza e Zingales (2008), non se obtiveron resultados significativos para a variable relativa ao feito de estar empregado. $\mathrm{Na}$ nosa opinión, iso pode obedecer, en parte, ao feito de que a mostra de estudo está integrada maioritariamente por persoas de máis de 50 anos, onde unha gran parte está xubilada (50,3\%).

En relación coa variable que identifica a propiedade dunha vivenda, reflexo tamén do estatus económico dos individuos, non puidemos probar a súa relevancia nos modelos estimados -non se inclúe no cadro-, non podendo concluír así que actúe como investimento alternativo fronte á participación no mercado bolsista. Iso difire dos resultados atopados por Vestman (2012); aínda que pode vir explicado pola idiosincrasia da cultura española onde o feito de ter unha casa en propiedade está firmemente enraizado. Segundo Ampudia Frade (2013), o 81,3\% dos fogares españois son propietarios da súa vivenda principal, fronte a un $68,3 \%$ no caso dos estadounidenses, percibindo iso como un investimento "básico" fronte a outras alternativas.

Tampouco se atopou evidencia de que o xénero exerza unha influencia sobre a participación no mercado de valores, polo que a hipótese suscitada que afirma que os homes participan máis no mercado non se pode confirmar, do mesmo xeito que nas investigacións de Kaustia e Torstila (2011) e Khorunzhina (2011).

De forma análoga, a evidencia empírica non permite confirmar a hipótese relativa ao número de fillos. Estes resultados difiren dos atopados por Christiansen, Joensen e Rangvid (2010a), onde se ratificaba a hipótese de que a participación diminúe a medida que o número de fillos aumenta. É probable que estas diverxencias se deriven dos diferentes perfís que integran ambas mostras. Así, a mostra de Christiansen, Joensen e Rangvid (2010a) incorpora a individuos que van dende os 20 ata os 60 anos, mentres que a nosa sitúa a metade dos individuos por enriba dos 65 anos. A esta idade, é de esperar que os fillos se atopen independizados e non actúen como unha barreira ás decisións de investimento de seus pais.

No referente á confianza, a diferenza do traballo de Guiso, Sapienza e Zingales (2008), non se atopou evidencia que permita confirmar a hipótese de que ante un maior nivel de confianza, a participación tamén será maior. Este feito podería ser consecuencia, en parte, da forma como se mediu a variable. Esta foi definida como confianza noutras persoas, e non como confianza nas institucións ou asesores financeiros; é dicir, trátase dunha medida xeral da confianza e non dunha medida específica en relación a cuestións financeiras.

De forma análoga, non se atopou evidencia que soporte a hipótese de que as preferencias políticas inflúen na participación no mercado de valores. No traballo de Kaustia e Torstila (2011) confirmouse que a xente "de esquerdas" participaba menos no mercado, mentres que Laakso (2010) atopou que a xente "de dereitas" era máis propensa a investir. O feito de que non se poida confirmar esta hipótese para o caso español pode deberse, en parte, a que en España, nestes momentos, non existe unha diferenza tan marcada entre a "dereita?" e a "esquerda" política. De feito, na enquisa SHARE para España, das 1.336 
persoas que responderon a esta pregunta, máis do $40 \%$ situouse no punto 5 nunha escala de 1 a 10 -onde 1 e 10 representan, respectivamente, ideoloxías próximas á esquerda e á dereita políticas-; é dicir, que a maioría dos participantes non se situaron políticamente.

En canto á relixiosidade, non se puido confirmar a influencia da práctica dunha relixión no mercado de valores. Este resultado difire do atopado por Laakso (2010). Unha explicación plausible a esta non significatividade pode estar relacionada coa definición da variable, pois se asocia o acto de rezar co de ter unha afiliación relixiosa definida, o cal non tería por que ser estrictamente certo, xa que na actualidade existe unha gran parte da poboación crente, pero non practicante.

Por último, tampouco se atopou evidencia de que a satisfacción vital e a interacción social inflúan na participación no mercado de valores. Estes resultados difiren dos atopados por Alimohammadisagvand e Matos (2012) e Laakso (2010).

\section{CONCLUSIÓNS}

A participación no mercado de valores é un tema académico recorrente, pois resulta moi controvertido que os niveis de participación sigan tan baixos malia os avances que vivimos nos últimos anos no que se refire á tecnoloxía e aos produtos financeiros. Daí derívase o interese do seu estudo, tamén para o caso español, onde os traballos centrados neste ámbito xeográfico son limitados, do mesmo xeito que sucede no caso latinoamericano. A análise econométrica consistiu na realización de estimacións probit utilizando unha mostra de datos creada a partir da enquisa SHARE para España no ano 2011. Os resultados amosan que os determinantes da decisión individual de investir no mercado de valores son a idade, a educación e a aversión ao risco. En concreto, a relación entre a idade e a participación resulta non ser lineal, pois ata unha determinada idade, a participación vai descendendo debido ás cargas que iso supón pero, a partir de dita idade, os saldos dispoñibles para investir son maiores, producíndose un cambio de tendencia. Coa educación, a relación é claramente positiva, pois a maior número de anos de estudo, maior é a participación no mercado, o cal resulta sinxelo de entender, pois tamén serán maiores os coñecementos e habilidades dos que dispón o individuo. Para rematar, a aversión ao risco exerce unha influencia negativa, como cabería esperar, xa que os individuos que non están dispostos a asumir riscos participan no mercado de valores en menor medida. Ademais dos determinantes mencionados, que fan referencia á teoría máis tradicional, o uso de internet tamén resulta un factor significativo á hora de explicar a participación. Iso está motivado pola revolución tecnolóxica que alterou o modo de participar no mercado, ata converterse nunha operación relativamente sinxela que calquera usuario pode realizar a través de Internet.

Este traballo contribúe á literatura existente porque aporta evidencia inédita do mercado español e, dada a proximidade cultural e económica, pode constituír un punto de partida adecuado para a análise de Latinoamérica que tamén rexistra niveis baixos de participación no mercado de valores. Este traballo tamén presenta limitacións, fundamentalmente, referidas á fonte de datos utilizada. En concreto, a pregunta que identifica o nivel de cultura financeira do participante foi só contestada por menos dun $9 \%$ da mostra, o que de facto limita a súa inclusión nos modelos econométricos. Por tanto, sería importante a procura dunha resposta no participante na enquisa que corrixise o baixo índice, así como a formulación de preguntas adicionais para medir este concepto, xa que medir os coñecementos financeiros dunha persoa a través dunha soa pregunta pode non aportar unha visión completa. Ademais, en relación coas variables relativas ás actividades sociais, sería conveniente indagar máis sobre a súa medición e posible influencia dada a importancia dos "efectos de grupo". Esta investigación é susceptible de ampliacións, entre as que se destacan dúas. En primeiro lugar, sería conveniente aumentar o ámbito de estudo a outras zonas xeográficas para realizar comparativas entre 
países. Desta forma, poderíase analizar si existen diferenzas culturais a nivel de país que expliquen a escasa participación da poboación española no mercado de valores. En segundo lugar, habería que explotar a enquisa utilizando a mostra correspondente aos datos de panel. Esta alternativa permitiría comprobar se a decisión de investir nos mercados de valores a través de accións ou fondos de investimento viuse afectada pola crise económico-financeira na que España está inmersa dende o ano 2007.

BIBLIOGRAFÍA

AlimOHAMMADISAGVAND, B.; Matos A. (2012): "Behavioral determinants of stock market participation" (Tesina). Suecia: Lund University.

AlMENBERG, J.; DREBER, A. (2011): Gender, stock market participation and financial literacy. (Working Paper, 737). Suecia: SSE/ EFI.

AMPUDIA, M. (2013): "Stockholding in Spain", Journal of the Spanish Economic Association, 4, pp. 415-435.

Chile. Banco Central de Chile (2013): Encuesta Financiera de Hogares: Metodología y principales resultados EFH 2011-2012, pp. 1-45.

BARBER, B.; ODEAN, T. (2001): "Boys Will Be Boys: Gender, Overconfidence, and Common Stock Investment", Quarterly Journal of Economics, 116(1), pp. 261-292.

Bertocchi, G.; BRUnetTI, M; TORRICELLI, C. (2009): "Marriage and Other Risky Assets: A Portfolio Approach", Journal of Banking \& Finance, 35, pp. 2902-2915.

BoGAN, V. (2008): "Stock market participation and the Internet", Journal of Financial and Quantitative Analysis, 43, pp. 191-212.

Christelis, D.; JaPPELli, T.; PADUla, M. (2010): "Cognitive abilities and portfolio choice", European Economic Review, 54, pp. 18-38.

Christiansen, C.; Joensen, J.; RANGVid, J. (2010a): Fiction or fact: systematic gender differences in financial investments?. (Working Paper EFA 2007 Ljubljana Meetings Paper ).

CHRISTIANSEN, C., JoENSEN, J. S. y RANGVID, J. (2010b): The effects of marriage and divorce on financial investments: learning to love or hate risk? (CREATES Research Paper, 2010-57). Dinamarca: School of Economics and Management, University of Aarhus.

Cocco, J. (2005): "Portfolio choice in the presence of housing", The Review of Financial Studies, 18, pp. 535-567.

Cole, S.; PAULSON, A.; SHASTRY, G. (2012): Smart money: the effect of education on financial behavior, (Working Paper, 09-071). Estados Unidos: Harvard Business School

CONSTANTINIDES, G.; DONALSON, J.; MEHRA, R. (2002): “Junior can't borrow: a new perspective of the equity premium puzzle", Quartely Journal of Economics, 117, pp. 269-296.

DireR, A.; VisSER, M. (2013): "Portfolio choice and financial advice", Finance: revue de l'Association Française de Finance, 34, pp. 35-64.

DOHMEN, T.; FAlK, A.; HufFman, D.; SunDE, U.; SChUPP, J.; WAGNER, G. (2011): "Individual risk attitudes: measurement, determinants and behavioral consequences", Journal of the European Economic Association, 9, pp. 522-550.

FUJIKI, H.; HIRAKATA, N.; SHIOJI, E. (2012): Aging and household stockholdings: Evidence from Japanese Household Survey Data. (IMES Discussion Paper Series, 12-E-17). Japón: Banco de Japón.

GARCíA, R. (2013): The effect of education on financial market participation: evidence from Chile. (Working Paper, 2013-01). Chile: Pontificia Universidad Católica de Chile.

GEORGARAKOS, D.; INDERST, R. (2011): "Financial advice and stock market participation", Conference on "Household finance and consumption". Luxemburgo: Banco Central Europeo y Banco Central de Luxemburgo. 
Guiso, L.; SAPIENZA, P.; Zingales, L. (2008): "Trusting the stock market", The Journal of Finance, 63, pp. 2557-2599.

GUISO, L.; SODINI, P. (2012): Household Finance. An emerging field. (Working Paper CEPR Discussion Papers, 8934). Londres: Centre for Economic Policy Research.

HALKO, M.; KAUSTIA, M.; AlANKO, E. (2011): “The gender effect in risky asset holding”, Journal of Economic Behavior and Organization, 83, pp. 66-81.

HANUSHEK, E.; WOESSMANN, L. (2008): "The role of cognitive skills in economic development", Journal of Economic Literature, 46, pp. 607-668.

HoNG, H.; KUBIK, J.; STEIN, J. (2004): “Social interaction and stock-market participation”, The Journal of Finance, 59, pp. 137-163.

JAPPELLI, T. (2010): "Economic literacy: an international comparison", The Economic Journal, 120, pp. 429-451.

KAUSTIA, M.; TORSTILA, S. (2011): "Stock market aversion? Political preferences and stock market participation", Journal of Financial Economics, 100, pp. 98-112.

KHORUNZHINA, N. (2011): Dynamic stock market participation of households. (Working Paper Munich Personal RePec Archive -MPRA-, 35310). Alemania: Biblioteca Universtiraia de Munich.

LAAKSO, E. (2010): Stock market participation and household characteristics in Europe, (Tesina). Finlandia: Aalto University School of Economics. < http:/ / epub.lib.aalto.fi/ en/ ethesis/ pdf/ 12385/ hse ethesis_12385.pdf >

LOVE, D. A. (2010): "The Effects of Marital Status and Children on Savings and Portfolio Choice", Review of Financial Studies, Vol. 23; 385-432.

Pellicer-Gallardo, M. (2005): Education and financial market participation. (Working Paper, 51). Italia: Padova University.

PURI, M.; ROBINSON, D. (2007): "Optimism and economic choice", Journal of Financial Economics, 86, pp. 71-99.

SERRANO, C.; HoESLI, M. (2009): Housing and its role in the household portfolio in Colombia. (Research Paper, 10-01). Génova: Swiss Finance Institute.

SHILleR, R. J. (1984): "Stock Prices and Social Dynamics", Brookings Papers on Economic Activity, 2, pp. 457-498.

SPATARO L.; CORSINI L. (2013): Endogenous financial literacy, saving and stock market participation. (Working Paper MPRA, 44342). Alemania: Biblioteca de la Universidad de Munich.

SUNDÉN, A.; SURETTE, B. (1998): "Gender differences in the allocation of assets in retirement savings plans", American Economic Review, 88, pp. 207-211.

VAN RoOIJ, M.; LUSARDI, A.; AlesSIE, R. (2011): "Financial literacy and stock market participation", Journal of Financial Economics, 101 (2), pp. 449-472.

VESTMAN, R. (2012): Limited stock market participation among renters and home owners, (Working Paper, 549). Society for Economic Dynamics.

VisSinG-JORGENSEN, A. (2004): "Perspectives on behavioral finance: Does irrationality disappear with wealth? Evidence from expectations and actions", en M. Gertler y K. Rogogg [ed.]: NBER Macroeconomics Annual 2003, pp. 139-194. Estados Unidos: The MT Press.

YoonG, J. (2010): Financial Illiteracy and Stock Market Participation: Evidence from the RAND American Life Panel, (Working Paper, 2010-29). Pension Research Council.

Anexo on line: http:/ / www.usc.es/ revistas/ index.php/ rge

Articles at Ideas.Repec: http:// https:/ / ideas.repec.org/ s/ sdo/ regaechtml 
Anexo 1

Tabla 4: Medida de las variables

\begin{tabular}{|c|c|c|}
\hline GRUPO & FACTOR & MEDIDA \\
\hline \multirow[t]{2}{*}{ DEMOGRÁFICO } & Idade & $\begin{array}{l}\text { Logaritmo natural da idade -medida en anos-. } \\
\text { Logaritmo natural da idade -medida en anos- ao cadrado }\end{array}$ \\
\hline & Xénero & Dicotómica con valores: $1=$ home, $0=$ muller. \\
\hline \multirow[t]{2}{*}{ FAMILIAR } & $\begin{array}{l}\text { Estado } \\
\text { civil }\end{array}$ & $\begin{array}{l}\text { Dicotómica con valores: } 1=\text { con compromiso de parella (Os } \\
\text { enquisados están casados e viven con cónxuxe ou están } \\
\text { inscritos como parellas de feito); } 0=\text { sen compromiso de } \\
\text { parella. }\end{array}$ \\
\hline & $\begin{array}{l}\text { Número } \\
\text { de fillos }\end{array}$ & Logaritmo natural do número total de fillos/ as. \\
\hline \multirow{3}{*}{ ECONÓMICO } & Renda & $\begin{array}{l}\text { Logaritmo natural da renda mensual total do fogar despois } \\
\text { de impostos. }\end{array}$ \\
\hline & Ocupación & $\begin{array}{l}\text { Dicotómica con valores: } 1=\text { a persoa entrevistada defínese } \\
\text { como traballadora (por contra propia ou axena); } 0=\mathrm{a} \\
\text { persoa entrevistada non traballal. }\end{array}$ \\
\hline & $\begin{array}{r}\text { Propiedade } \\
\text { de vivenda }\end{array}$ & $\begin{array}{l}\text { Dicotómica con valores: } 1=\text { propietario/a de una vivenda; } \\
0=\text { no propietario/ a de una vivenda. }\end{array}$ \\
\hline \multirow[b]{2}{*}{ EDUCACIÓN } & Educación & $\begin{array}{l}\text { Logaritmo natural dos anos de estudo a tempo completo da } \\
\text { persoa entrevistada. }\end{array}$ \\
\hline & $\begin{array}{l}\text { Cultura } \\
\text { financeira }\end{array}$ & $\begin{array}{l}\text { Dicotómica con valores: } 1=\text { a persoa entrevistada ten } \\
\text { coñecementos financeiros; } 0=a \text { persoa entrevistada carece } \\
\text { de alfabetización financeira. }\end{array}$ \\
\hline Risco & $\begin{array}{l}\text { Aversión } \\
\text { a risco }\end{array}$ & $\begin{array}{l}\text { Dicotómica con valores: } 1=\text { a persoa declara aversión ao } \\
\text { risco; } 0=\text { a persoa defínese como propensa ao risco. }\end{array}$ \\
\hline \multirow{6}{*}{ OUTROS } & Confianza & $\begin{array}{l}\text { Dicotómica con valores: } 1=\text { a persoa manifesta ter } \\
\text { confianza; } 0=a \text { persoa no manifesta ter confianza. }\end{array}$ \\
\hline & Internet & $\begin{array}{l}\text { Dicotómica con valores: } 1=\text { a persoa usa Internet } \\
\text { frecuentemente; } 0=a \text { persoa no usa a rede frecuentemente. }\end{array}$ \\
\hline & $\begin{array}{l}\text { Satisfacción } \\
\text { vital }\end{array}$ & $\begin{array}{l}\text { Dicotómica con valores: } 1=\text { a persoa considerase satisfeita } \\
\text { coa su vida; } 0=a \text { persoa non está satisfeita coa súa vida. }\end{array}$ \\
\hline & $\begin{array}{l}\text { Preferencias } \\
\text { políticas }\end{array}$ & $\begin{array}{l}\text { Dicotómica con valores: } 1=\text { a persoa afirma ter una } \\
\text { ideoloxía de "dereita"; } 0=a \text { persoa declara non ter posición } \\
\text { política ou en favor dunha ideoloxía de "esquerda". }\end{array}$ \\
\hline & Relixiosidade & $\begin{array}{l}\text { Dicotómica con valores: } 1=\text { a persoa practica unha relixión; } \\
0=\text { a persoa non practica unha relixión. }\end{array}$ \\
\hline & $\begin{array}{l}\text { Interacción } \\
\text { social }\end{array}$ & $\begin{array}{ll}\text { Dicotómica con valores: } 1=\text { a persoa } & \text { participa en } \\
\text { actividades sociais; } 0=\text { a persoa non participa en } & \text { en } \\
\text { actividades sociais. } & \end{array}$ \\
\hline
\end{tabular}

Fonte: elaboración propia.

Anexo 2

$$
Y_{i}=G(z)=\int_{-\infty}^{z} \frac{1}{(2 \pi)^{\frac{1}{2}}} e^{\frac{-z^{2}}{2}} d z+u_{i} \quad \text { con } \mathrm{z}_{\mathrm{i}}=\mathrm{X}_{\mathrm{i}} \beta
$$

$G(z)$ é a función de distribución cumulativa dunha variable aleatoria normal tipificado. $Y_{\mathrm{i}}$ é a variable dependente con dous valores posibles: cero ou unidade; $u_{i}$ é unha variable 
aleatoria distribúese $\mathrm{N}\left(0, \sigma^{2}\right)$; $\mathrm{X}_{\mathrm{i}}$ recolle o conxunto de variables independentes. Neste traballo, o conxunto de variables explicativas é resumida en:

$$
\begin{gathered}
\mathrm{X}_{\mathrm{i}} \beta=\beta_{1}+\beta_{2} \mathrm{X}_{\text {Idade }}+\beta_{3} \mathrm{X}_{\text {Idade }}{ }^{2}+\beta_{4} \mathrm{X}_{\text {Aversión_risco }}+\beta_{5} \mathrm{X}_{\text {Educación }}+\beta_{6} \mathrm{X}_{\text {Ocupación }}+ \\
\beta_{7} \mathrm{X}_{\text {Xénero }}+\beta_{8} \mathrm{X}_{\text {No _ofllos }}+\beta_{9} \mathrm{X}_{\text {Confianza }}+\beta_{10} \mathrm{X}_{\text {Internet }}+\beta_{11} \mathrm{X}_{\text {Preferencias_políticas }}+ \\
\beta_{12} \mathrm{X}_{\text {Relixiosidade }}+\beta_{13} \mathrm{X}_{\text {Satisfacción_vital }}
\end{gathered}
$$

\begin{tabular}{|c|c|c|c|c|c|c|c|c|}
\hline & Modelo 1 & Modelo 2 & Modelo 3 & Modelo 4 & Modelo 5 & Modelo 6 & Modelo 7 & Modelo 8 \\
\hline & $-4,06^{*}$ & $-4,22^{*}$ & $-2,07$ & $-4.22^{*}$ & $-4.26^{*}$ & $-4.93^{*}$ & $-4.14^{*}$ & $-5.26^{*}$ \\
\hline Idade & $(1,92)$ & $(1,93)$ & $(1,98)$ & (1.93) & (1.88) & $(2.22)$ & (1.86) & $(2.18)$ \\
\hline \multirow{2}{*}{ Idade $^{2}$} & $0,51^{*}$ & $0,52 *$ & 0,26 & $0.52 *$ & $0.53 *$ & $0.62 *$ & $0.52 *$ & $0.66^{*}$ \\
\hline & $(0,23)$ & $(0,24)$ & $(0,24)$ & $(0.24)$ & $(0.23)$ & $(0.27)$ & $(0.23)$ & $(0.27)$ \\
\hline \multirow{2}{*}{$\begin{array}{l}\text { Aversión a } \\
\text { riesgo }\end{array}$} & $-0,19 * * *$ & $-0,19 * * *$ & $-0,15^{* * *}$ & $-0.19 * * *$ & $-0.16^{* * *}$ & $-0.14 * * *$ & $-0.16^{* * *}$ & $-0.15^{* * *}$ \\
\hline & $(0,04)$ & $(0,04)$ & $(0,04)$ & $(0.04)$ & $(0.04)$ & $(0.04)$ & $(0.04)$ & $(0.04)$ \\
\hline \multirow{2}{*}{ Educación } & $0,04^{* *}$ & $0,04^{* *}$ & $0,04^{*}$ & $0.05^{* *}$ & 0.03* & 0.03 & 0.03 & 0.04 \\
\hline & $(0,02)$ & $(0,02)$ & $(0,02)$ & $(0.02)$ & $(0.02)$ & $(0.02)$ & $(0.02)$ & $(0.02)$ \\
\hline \multirow{2}{*}{ Ocupación } & 0,00 & 0,00 & $-0,01$ & 0.00 & -0.01 & -0.01 & -0.01 & -0.02 \\
\hline & $(0,02)$ & $(0,02)$ & $(0,02)$ & $(0.02)$ & $(0.02)$ & $(0.02)$ & $(0.02)$ & $(0.02)$ \\
\hline \multirow{2}{*}{ Xénero } & & 0,01 & 0,03 & 0.02 & 0.01 & 0.02 & 0.02 & 0.01 \\
\hline & & $(0,02)$ & $(0,02)$ & $(0.02)$ & $(0.02)$ & $(0.02)$ & $(0.02)$ & $(0.02)$ \\
\hline № de fillos & & & $\begin{array}{c}0,00 \\
(0,02)\end{array}$ & & & & & \\
\hline \multirow[t]{2}{*}{ Confianza } & & & & 0,00 & 0,00 & 0.01 & 0.00 & 0.00 \\
\hline & & & & $(0,02)$ & $\frac{(0,02)}{0,06 * *}$ & $\frac{(0.02)}{0.07 * *}$ & $\frac{(0.02)}{0.06 * *}$ & $\frac{(0.02)}{0.0 \% * *}$ \\
\hline Internet & & & & & $\begin{array}{l}0.06^{* *} \\
(0.03)\end{array}$ & $\begin{array}{l}0.07 * * \\
(0.03)\end{array}$ & $\begin{array}{l}0.0 b^{* *} \\
(0.03)\end{array}$ & $\begin{array}{l}0.08^{* *} \\
(0.03)\end{array}$ \\
\hline Preferencia & & & & & & 0.04 & & 0.04 \\
\hline s políticas & & & & & & $(0.02)$ & & $(0.02)$ \\
\hline $\begin{array}{l}\text { Relixiosida } \\
\text { de }\end{array}$ & & & & & & & $\begin{array}{c}0,01 \\
(0,02)\end{array}$ & \\
\hline $\begin{array}{l}\text { Satisfacción } \\
\text { vital }\end{array}$ & & $\begin{array}{c}0,02 \\
(0,02) \\
\end{array}$ & & & & & & \\
\hline $\mathrm{N}$ & 879 & 879 & 740 & 875 & 875 & 735 & 873 & 701 \\
\hline Wald & $65,22^{* * *}$ & $67,34^{* * *}$ & 52,65 *** & 67,41 *** & $69,46^{* * *}$ & $64,89 * * *$ & i8,35***(10 & $71,83 * * *(1$ \\
\hline $\mathrm{X}^{2}$ (g.l.) & (5) & (6) & (7) & (7) & (8) & (9) & ) & 0) \\
\hline $\begin{array}{l}\mathrm{R}^{2} \\
\text { McFadden }\end{array}$ & 0,16 & 0,16 & 0,16 & 0,16 & 0,18 & 0,1997 & 0,19 & 0,21 \\
\hline $\begin{array}{l}\text { Pseudo } \\
\text { likelihood }\end{array}$ & $-178,71$ & $-178,32$ & $-131,90$ & $-178,08$ & $-173,14$ & $-154,42$ & $-154,42$ & $-145,61$ \\
\hline $\begin{array}{c}\text { Criterio de } \\
\text { Akaike (g.l.) }\end{array}$ & $\begin{array}{c}369,42 \\
(6)\end{array}$ & $\begin{array}{c}370,64 \\
(7)\end{array}$ & $\begin{array}{c}279,81 \\
(8)\end{array}$ & $\begin{array}{c}372,16 \\
(8)\end{array}$ & $\begin{array}{c}364,28 \\
(9)\end{array}$ & $\begin{array}{c}328,84 \\
(10)\end{array}$ & $\begin{array}{c}330,84 \\
(11)\end{array}$ & $\begin{array}{c}313,22 \\
(11)\end{array}$ \\
\hline
\end{tabular}

Táboa 7: Estimacións de Probit a decisión de participar no mercado de accións

Nota: A Táboa 7 mostra as estimacións de probit da decisión de investimento en accións e / ou fondos de investimento por parte de individuos analizados. En especial, distínguense efectos parciales medios de cada estimación. Os símbolos $* * *, * * \mathrm{e}^{*}$ indican niveis de significatividade $0,1 \%, 1 \%$ e $5 \%$, respectivamente. Erros estándar robustos están en parénteses. G. L. Refírese aos graos de liberdade. Wald X2 é unha proba de bondade de axuste, asintótica distribuída como unha X2 baixo a hipótese nula de ausencia de significación conxunta das variables explicativas (excluíndo temporal dicotômica), validou seu poder explicativo (graos de liberdade entre parénteses). 